\title{
COMPULSORY ADMISSION TO A PORTUGUESE ACUTE PSYCHIATRIC UNIT: RETROSPECTIVE STUDY OF 287 INVOLUNTARY ADMISSIONS IN 2016-2017
}

\author{
C. Fernandes Santos, F. Fernandes Martins, N. Descalço, A. Carapucinha, A. Barcelos, A. B. Medeiros, \\ C. Miranda, M. Bernardo, P. Casimiro, T. Mendonça, V. Henriques, F. Gonçalves \\ Department of Psychiatry and Mental Health, Hospital Garcia de Orta - Almada, Portugal
}

\section{OBJECTIVES}

To determine a specific profile of the patient with high risk of psychiatric compulsory admission.

\section{BACKGROUND}

In Portugal, the principles of Mental Health Policy are established by The Mental Health Act, published in 1998 and implemented in January 1999, regulating the compulsory detention of persons suffering from psychiatric disorders.

The authors analyze sociodemographic and clinical characteristics of compulsory admissions to a Portuguese acute psychiatric unit, responsible for the admissions of a population of 358.300 inhabitants.

\section{MATERIALS AND METHODS}

The case records of 287 involuntary admissions of 239 patients, from a total of 776 admissions to the Department of Psychiatry of Hospital Garcia de Orta between January 1, 2016 and December 31, 2017, were consulted retrospectively.

\section{RESULTS}
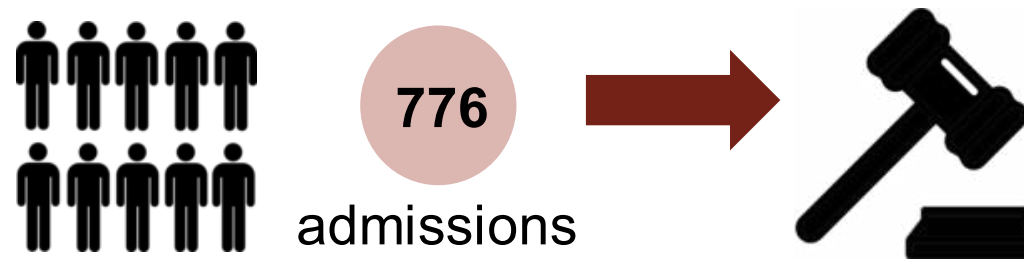

287

compulsory admissions admissions
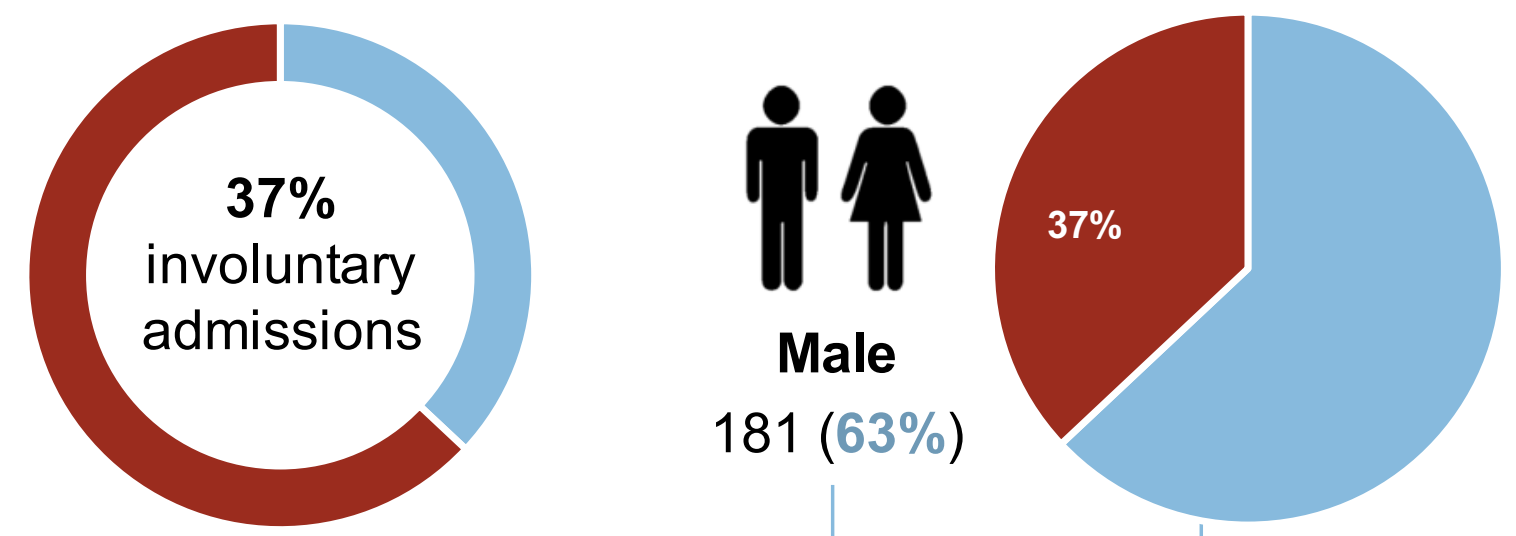

- Average Age | 43 y

Social Situation:

- Median Age 41 y

- Independent | 267 (93\%)

Min | 16 y ; Max | 85 y

- Homeless $\mid 7$ (2.4\%)

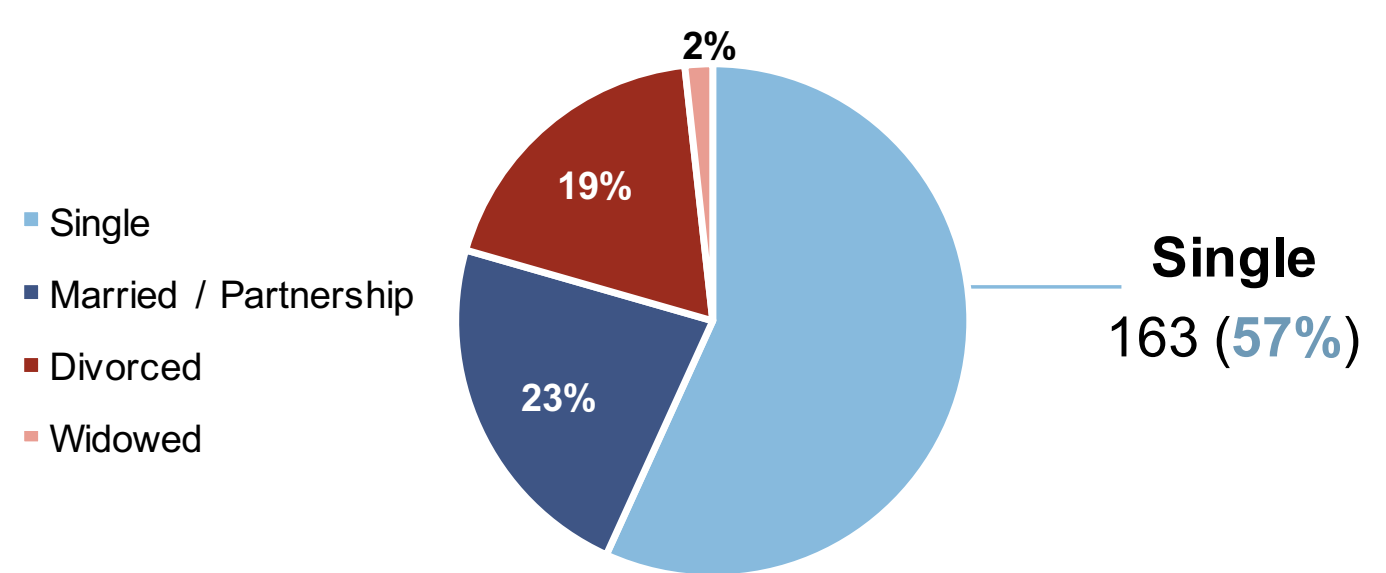

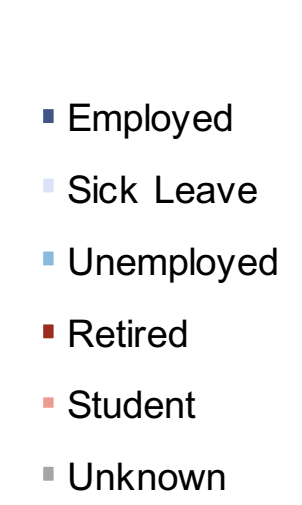

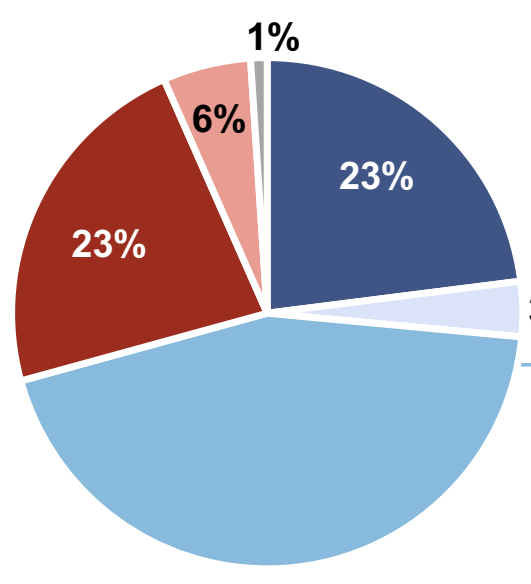

Duration of Admission:

- Average | 24 days

- Median | 19 days

- Min | 1 day; Max | 208 days

\section{Unemployed}

$127(44 \%)$

Substance Use:

- $187(65 \%)$

- >1 Substance| 105 $(56 \%)$

- Mainly tobacco and cannabis, followed by alcohol and cocaine.

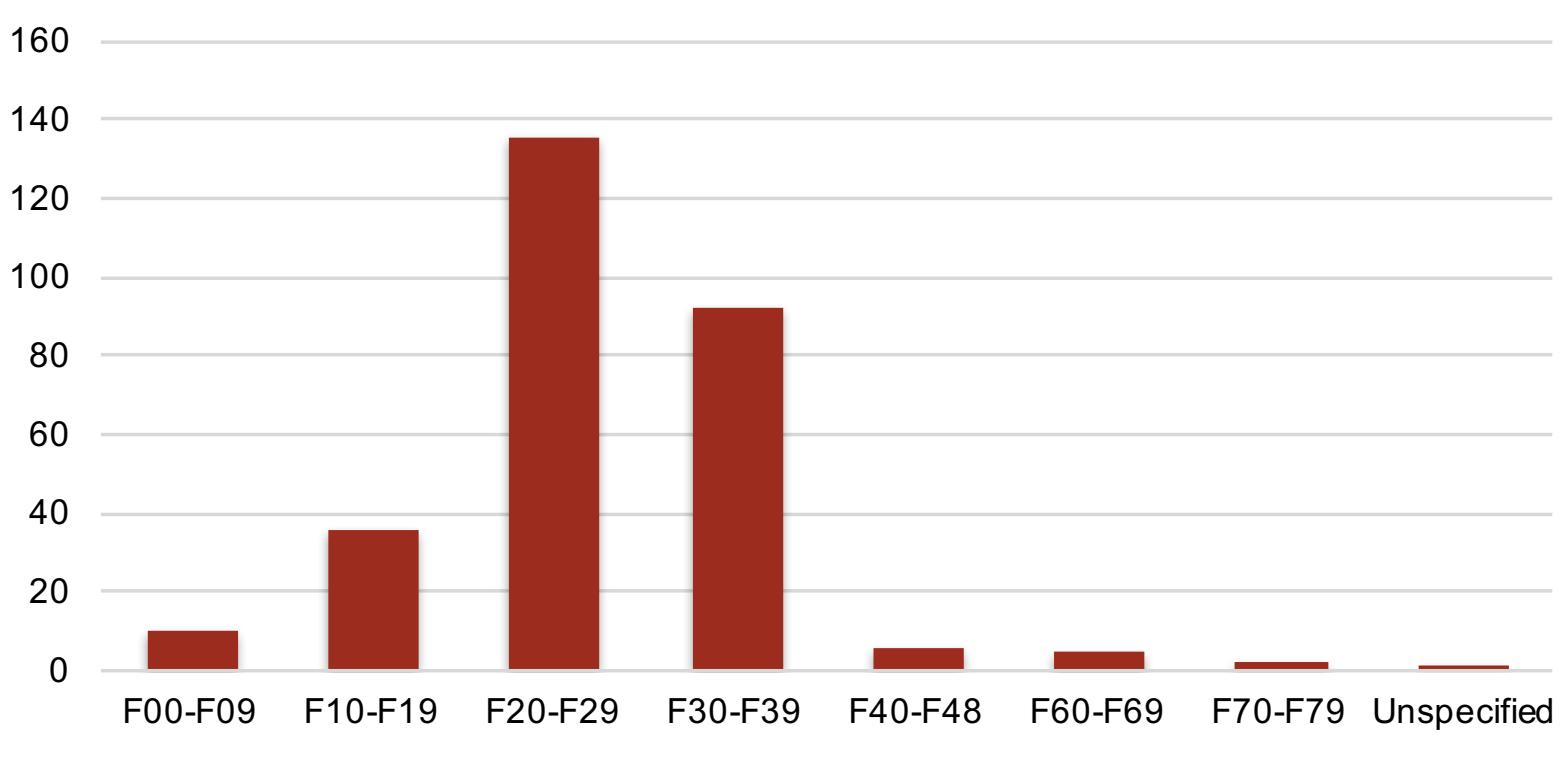

International Classification of Diseases - 10th revision (ICD-10)

- Schizophrenia (29\%), bipolar affective disorder, with both manic $(13 \%)$ and mixed $(9 \%)$ episodes, and unspecified psychosis $(8 \%)$ constituted the most frequent diagnoses;

- Patients presented several medical conditions, with an emphasis on cardiovascular and metabolic diseases essential hypertension ( $8.4 \%$ ), dyslipidemia $(4.2 \%)$ and obesity $(3.5 \%)$. HCV infection was also present in $3.5 \%$.

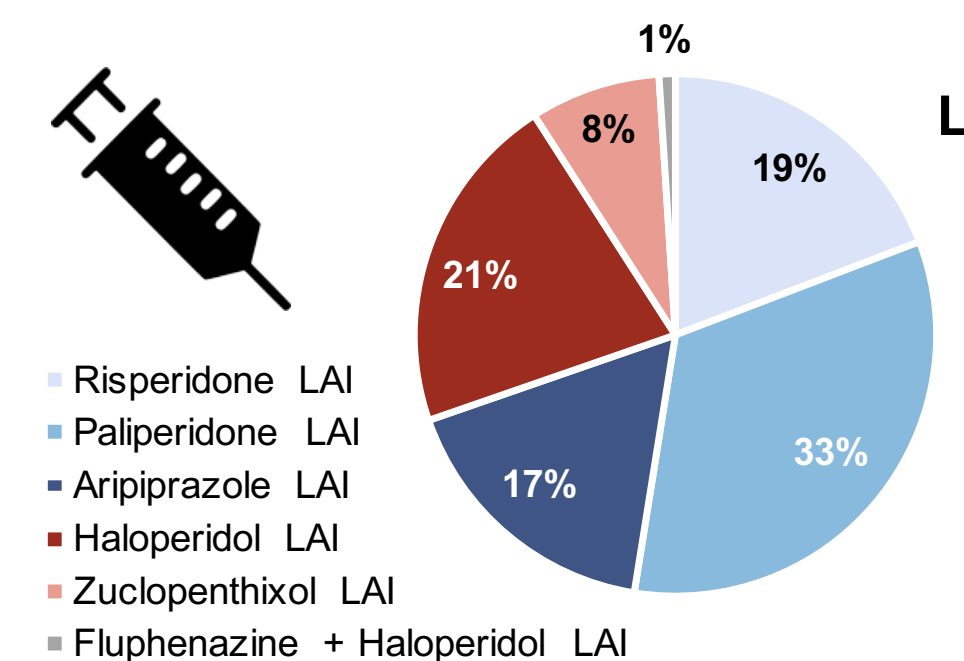

Long-Acting Injectable Antipsychotics (LAl) $132(46 \%)$

- $45(16 \%)$ patients discharged under Community Treatment Order.

\section{CONCLUSIONS}

The patient with high risk of compulsory admission is a middleaged single man, unemployed, with the diagnosis of schizophrenia and comorbid substance use, who needs inpatient treatment for about three weeks. The obtained results are comparable to those of similar studies.

REFERENCES: 1. Skokou M, Gouma P, Gourzis P. Compulsory admissions in southwest Greece 2010-2011: A descriptive report. Psychiatriki. 2017 Jul-Sep;28(3):265-273. 2. Almeida T, Molodynski A. Compulsory admission and involuntary treatment in Portugal. BJPsych Int. 2016 Feb 1;13(1):17-19. 3. Brissos S, Carita A, Vieira F. Compulsory admission to a Portuguese psychiatric hospital: retrospective study of 497 involuntary admissions. BMC Psychiatry. 2007;7(Suppl 1):P2. Published online 2007 Dec 19. 4. Duarte C, Wong F, Kwok WT, Lau KK, Chang MI, Ho CY. [Compulsory treatments in Macao: the first five years]. Acta Med Port. 2006 Jan-Feb;19(1):73-8. Epub 2006 Apr 30. 